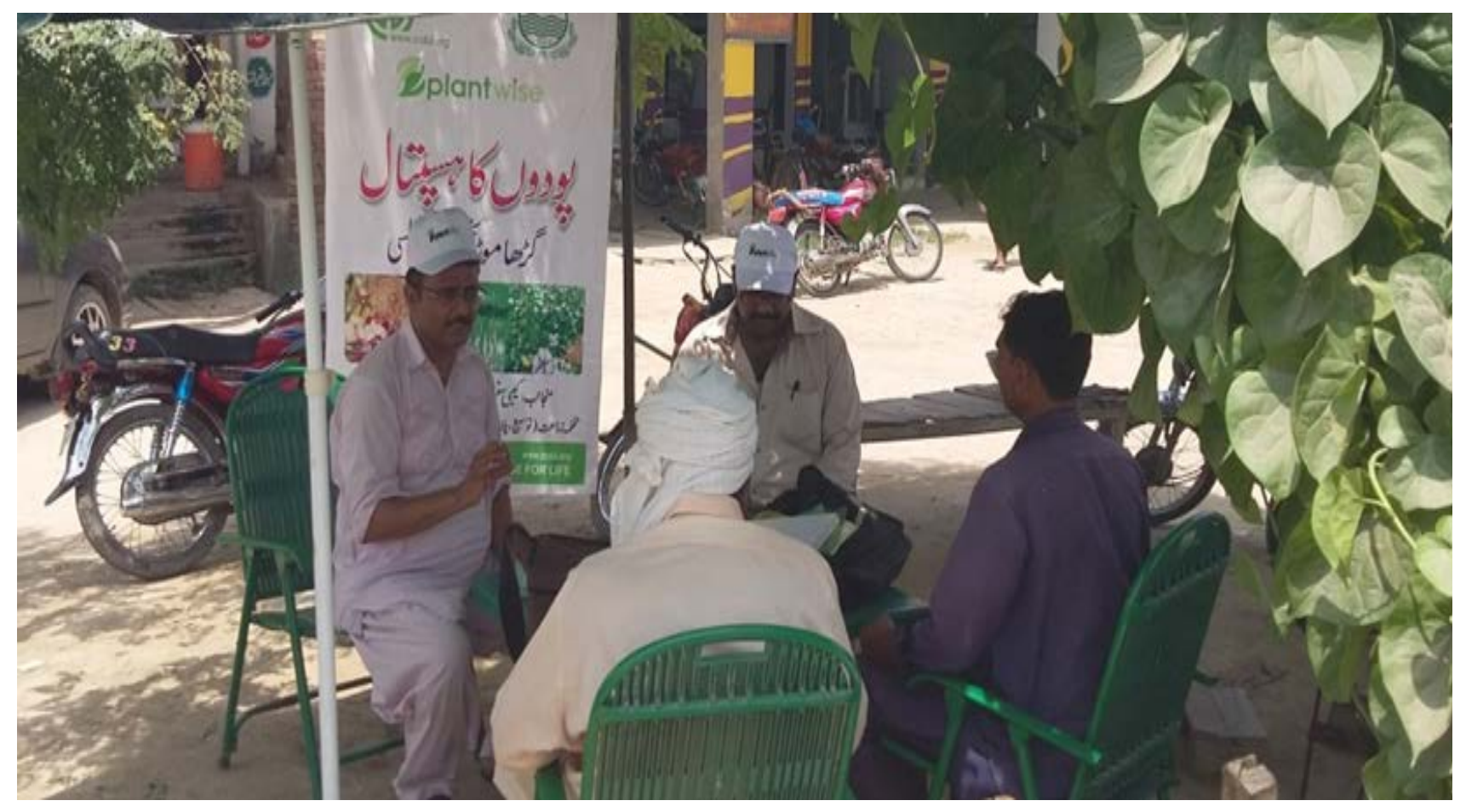

\title{
Plantwise Impact: Results and Lessons from Pakistan
}

\section{Juan Bonilla, Andrea Coombes, Adria Molotsky}

This publication is a digest of a mixed-methods evaluation report of the impacts of CABI's Plantwise programme in Pakistan (PW-P), undertaken by American Institutes for Research (AIR).

\section{Key messages}

- Qualitative data showed that the trainings implemented as part of the Plantwise program successfully prepared Agricultural Officers (AOs) to act as plant doctors and to provide relevant advice to farmers. Plant clinics also increased AO's direct contact with farmers.

- PW-P activities have led to some system-level changes in the geographic areas of focus for the evaluation. However, given the size of the program compared to the number of farmers, existing systems, and other external agriculture programs in the country, PW-P lacks the reach, scale, and influence to change systemic approaches to pest and disease control

- Results from quantitative studies show that Plantwise contributes to:

- Increased use of cultural practices such as planting early, weeding in a timely manner, or using traps.

- Pesticide risk reduction at the farmer level 
- Increased farm productivity of farmers of all crops who use plant clinics and who reported their crops having plant health issues.

- A cost-benefit analysis of Plantwise in Pakistan shows that estimated monetary benefits outweigh the costs of implementing the program at a benefit-cost ratio of 1.2:1 and an internal rate of return of $28 \%$.

\section{Background}

Plantwise is a global program initiated by CABI to increase food security and transform rural livelihoods by reducing crop losses. This is achieved through three interconnected activities. First, the program works through a network of plant clinics, where farmers can get actionable and science-based agricultural advice from AOs trained to work as plant doctors. Second, plant clinics are reinforced by the Plantwise Knowledge Bank, a gateway to online and offline plant health information, including diagnostic resources, pest management advice, and front-line pest data. Lastly, working in partnership with relevant partners, Plantwise strengthens national plant health systems from within, helping to establish frameworks for in-country pest surveillance and early warning systems. This empowers countries to respond quickly to emerging plant health problems.

The Plantwise program was launched in Pakistan in 2011 to reduce crop losses by gathering, organizing, managing and disseminating plant health information to smallholder farmers. By giving smallholder farmers the knowledge to lose less of what they grow, Plantwise helps them become more food secure and resistant to financial and climate shocks.

\section{Purpose}

In 2018, CABI commissioned the American Institutes for Research (AIR) to conduct a mixed-methods impact assessment of PW-P. The study used both quantitative and qualitative data collection methods including farmer surveys, interviews, and focus group discussions at national, provincial and local levels. A quasi-experimental approach was used to identify program impacts at the farm level. Lastly, administrative quantitative data on program costs was also used to conduct a cost-benefit analysis of the program. The study included one round of data collected at the end of 2018.

Plantwise was launched in Pakistan in 2011 in Punjab Province. Currently, this province has the highest levels of plant clinic coverage in the country (640 out

\section{Figure 1: Evaluation Districts in Punjab province} and Plant Clinic Locations

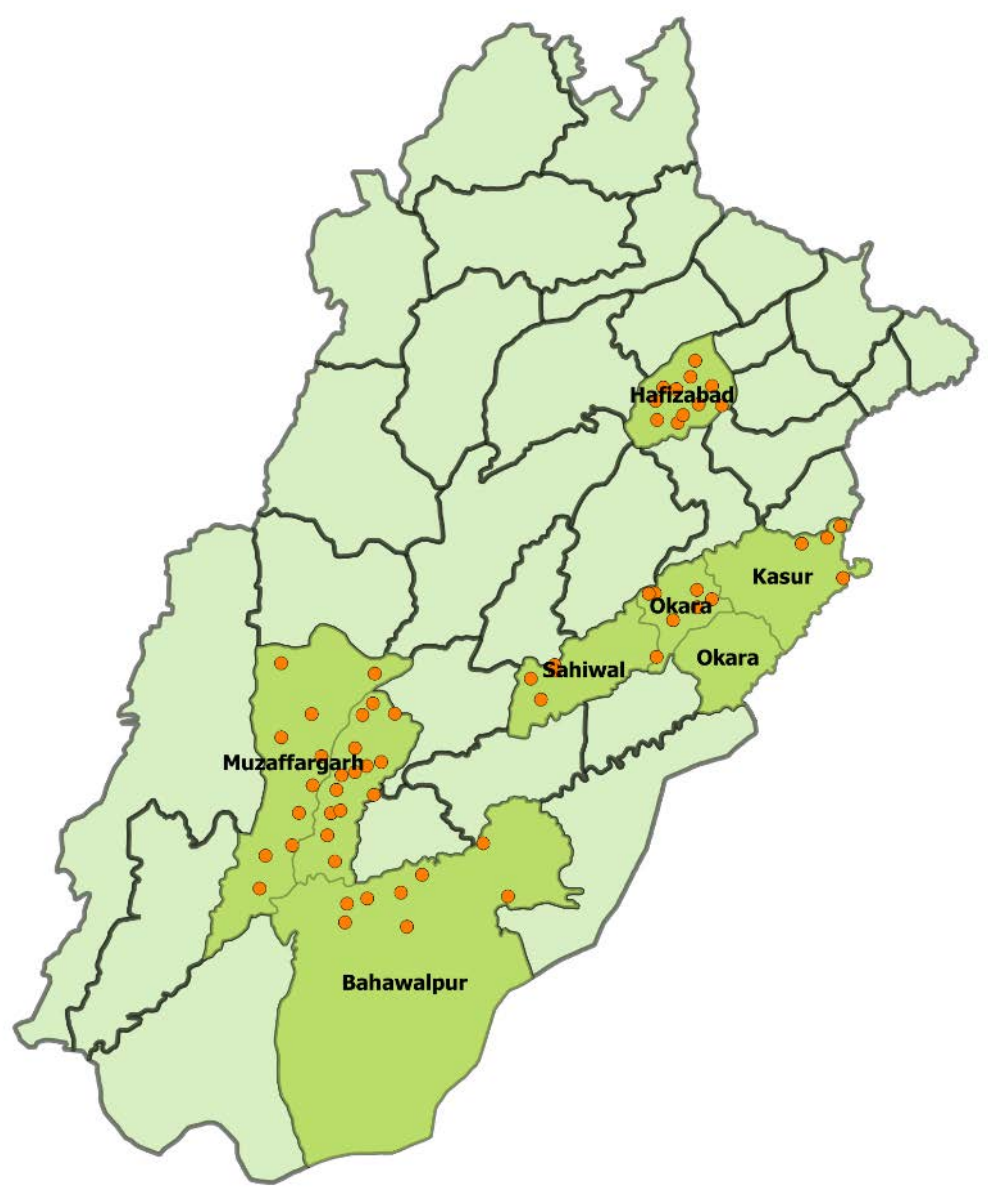
of 901 active clinics in Pakistan), which 
makes it an optimal location to conduct an evaluation of the program. As a result, seven districts in Punjab were identified to assess the impact of the program (Figure 1). These districts captured provincial variability in crop production, had a well-established set of plant clinics and have higher levels of plant clinic utilization.

The purpose of this brief is to present the findings from the impact assessment of the PW-P in terms of:

- program implementation

- changes to the plant health system

- measurable impacts at the farm-level

- benefits of the program relative to its costs

\section{Assessing the implementation of PW-P}

The impact of a program like Plantwise is ultimately a function of how it is implemented. Our analysis found that overall the plant clinics were implemented as intended. The trainings prepared AOs to act as plant doctors and provide high-quality advice, including accurate diagnosis and correct and actionable recommendations on how to manage the problem. Local program implementers believed that plant clinics ran smoothly after the training. One provincial official said that plant doctors were well-prepared because after the training they were able to "solve plant problems better". Officials reported that the plant doctors gain practical knowledge on pest diagnosis and management.

The main strengths of locating plant clinics in markets and the weekly clinic logistics were that the location and time were consistent and that the format provided farmers with direct access to AOs in a more neutral space. The clinics also increased AOs' direct contact with farmers, strengthening the relationship between AOs and farmers. Although the plant clinics did not appear to increase the total numbers of farmers seen by AOs in a week, they provided a unique opportunity for male farmers to easily access and consult plant doctors in a public space. However, female farmers did not visit the clinics due to the distance they had to travel to visit a clinic, and the fact that nearly all the plant doctors are men.

Challenges remained: AOs struggled to implement their responsibilities as plant doctors on top of their existing work without additional incentives and many plant doctors indicated that the number of chairs were too few and the quality of the umbrellas inadequate to shelter them and their clients from the heat. Finally, although plant doctors and government officials, noted the potential utility of the Plantwise Online Management System (POMS) and the Knowledge Bank, actual use was low. POMS, while used for data entry, was not used for systematic decision making across government.

\section{Assessing Plant Health System Change}

PW-P activities have led to system-level changes in the areas of focus for the evaluation. Officials (through 21 key informant interviews and 10 focus group discussions) said that PW-P data aligned with priorities for farmer extension and supplemented the data they collected on production, yields, and soil quality. In addition, all types of respondents valued the training plant doctors received and believed it improved diagnosis in those cases.

The data do not, however, indicate that these improvements in diagnosis have the reach needed to influence the system. There is also no evidence that data collected specifically from plant clinics are used in a systematic way to make provincial-level policy decisions on pest and disease outbreak and response. In addition, respondents indicated that PW-P had not changed interactions on plant health. 
Given the size of the programme compared to the number of farmers, existing systems, and other external agriculture programs in the country, PW-P currently lacks the reach, scale, and influence to change systemic approaches to pest and disease control country-wide.

\section{Identifying Farm-Level Impacts}

One key goal of the impact assessment was to determine to what extent PW-P is able to translate the institutional changes in the plant health system and the process through which the program is implemented into measurable impacts at the farm level. This was determined by assessing program impacts on intermediate and final outcomes, including cultural practices, input use, yields, value of yields, production costs and net income. A quasi-experimental approach to identify farm-level impacts was conducted in seven districts in Punjab with the final quantitative sample including a total of 1805 households from 120 communities. Across the study districts in the sample, wheat, cotton and rice represented $75 \%$ of the crops cultivated and $88 \%$ of the cultivated area. The study then focused on these three crops in the impact analysis given their relative importance in terms of agricultural production. For analysis, two samples were used: the full sample of farmers as well as a sub-sample of farmers that indicated they had encountered plant health problems during the last agricultural season. The study finds that PW-P exhibits some positive and statically significant impacts on agricultural practices, knowledge and practices for pesticide use, and value of yields and net income for farmers with plant health issues.

\section{Cultural Practices}

The analysis found a significant effect of plant clinic attendance increasing the number of good practices implemented by farmers by 0.11 from a mean of 6.48 to 6.59 practices. Farmers who attended plant clinics in the 12 months before the survey, regardless of whether they reported a plant health issue during that period, were 4 percentage points (pp) more likely to plant crops early and were 3 pp more likely to weed crops in a timely manner. For farmers who reported having a plant health issue in the last 12 months before the survey, those who attended plant clinics were $8 \mathrm{pp}$ more likely to plant crops early, $5 \mathrm{pp}$ more likely to weed in a timely manner, $5 \mathrm{pp}$ more likely to control pest and diseases by burning crop residue and $3 \mathrm{pp}$ more likely to use pheromone traps relative to farmers in the control group with plant health issues. Overall, plant clinic users implement, on average 0.26 more practices than the control group (7.07 cf 6.81). The results show that farmers who attend plant clinics and who have crops with plant health issues adopt more cultural pest management practices when compared to the overall sample.

\section{Inputs Use}

In terms of input use, plant clinic users spend 6\% more on seeds than those who don't attend plant clinics and plant clinic users are also $4 \mathrm{pp}$ less likely to use seeds from their own sources. The analysis found no significant effects of plant clinic attendance and usage of organic or inorganic fertilizer use.

Among the three key crops considered, almost all the farmers who grow cotton use pesticides compared to about $80 \%$ of farmers who grow wheat and rice. Clinic users were $5 \mathrm{pp}$ less likely to use pesticide. The results also showed a small effect of the program on the probability of not using pesticides that are banned or restricted by international agreements (i.e., red-listed pesticides) for wheat and rice production. While very few farmers use pesticides that are included in the red list ( $1 \%$ and $3 \%$ of control wheat and rice farmers, respectively), wheat and rice clinic users are 1 and 2 percentage points less likely to use them, respectively. Use of red-list chemicals was highest for cotton growers with no positive effect of clinics. Despite not observing significant differences in the use of pesticides, there is evidence 
that farmers who attend plant clinics have safer practices related to pesticide usage. For example, the results show that there is a $5 \mathrm{pp}$ increase in wearing gloves and wearing a mask, a 4 pp increase in wearing goggles when spraying pesticides, and a 4 pp decrease in the propensity to store chemicals in living areas.

In addition, attending plant clinics has enabled farmers to adopt other Integrated Pest Management practices such as checking for plant health problems more regularly and responding to the problems more effectively. The results show that plant clinic attendance resulted in a 3 pp increase in checking for plant health problems on a regular basis and a $6 \mathrm{pp}$ decrease in not responding to the plant health problem.

\section{Access to Agricultural Information}

The results show that plant clinic users are receiving more information on agricultural topics. Farmers who attended plant clinics were more than $30 \mathrm{pp}$ more likely to report that they received information on seed varieties, pest control, fertilizer use, and agronomic practices. Only $34 \%$ of control farmers reported receiving improved pest information compared with $57 \%$ of treatment farmers over the same period. There were also statistically significant differences between clinic users and non-users on the usefulness of the advice they received on primary areas such as seed varieties, pest control, and fertilizer use with clinic users 2 to $4 \mathrm{pp}$ more likely to report finding the information useful. These results provide evidence about the level of satisfaction that users have from the services received at plant clinics.

\section{Productivity and Costs}

To estimate the impact of the PW-P program on crop productivity, data on crop production, value of crop production, area of production, and costs of inputs (including seed, pesticide, fertilizer, and labour) were used. When all crops were considered together, for all farmers whether or not they experienced a plant health problem, results showed no effect of plant clinic visits on yields, value of yields, or net income. However, when looking at individual crops, there was an $8 \%$ increase in net income for cotton producers visiting plant clinics whether or not a plant health problem was experienced.

Among the subsample of treatment farmers who attended plant clinics and reported having plant health issues, it was not possible to analyse crops separately as sample sizes were too small. However, there was an $8 \%$ increase in the value of the combined yield and in net income for all crops relative to the control farmers (see Table 1, panel A). To rule out that the impact on value of yields was because the control group experienced more plant health issues than those who attended clinics, the extent of damage (rated on a 10-point scale variable by farmers) of the plant health issue was controlled for (see Table 1, panel B). The results were not affected by controlling for this variable, and if anything, are better and more statistically significant, showing a $9 \%$ increase in net income. This indicates that the increase in yield value and net income for treatment farmers was not affected by the extent of the plant health issue being faced. Ultimately, these positive results provide evidence that plant clinics positively impact the productivity of farmers who face plant health issues. 
Table 1. Impacts on Value of Yields, and Costs for Farmers with Plant Health Issues.

\begin{tabular}{|c|c|c|c|c|}
\hline Outcome of interest & $\begin{array}{c}\text { Mean control } \\
\text { (PKR) }\end{array}$ & $\begin{array}{l}\text { Mean clinic } \\
\text { users (PKR) }\end{array}$ & $\begin{array}{l}\text { Impact } \\
\text { estimate- \% } \\
\text { change }\end{array}$ & $N$ \\
\hline \multicolumn{5}{|l|}{ Panel A. All crops } \\
\hline Value of production per acre (PKR/acre) & 70,263 & 76,880 & $8^{\star \star}$ & 934 \\
\hline Total cost per acre (PKR/acre) & 20,333 & 21,590 & 5 & 926 \\
\hline Cost of inorganic fertilizer per acre & 8,518 & 8,955 & 4 & 926 \\
\hline Pesticide cost per acre & 1,669 & 1,808 & 9 & 926 \\
\hline Net income (PKR/acre) & 44,356 & 48,050 & $8^{*}$ & 839 \\
\hline \multicolumn{5}{|c|}{ Panel B. All crops-controlling for severity of plant health Issue } \\
\hline Value of production per acre (PKR/acre) & 70,263 & 76,880 & 9 9* & 934 \\
\hline Total cost per acre (PKR/acre) & 20,333 & 21,590 & 6 & 926 \\
\hline Cost of inorganic fertilizer per acre & 8,778 & 8,604 & -2 & 926 \\
\hline Pesticide cost per acre & 1,620 & 1,755 & 8 & 926 \\
\hline Net income (PKR/acre) & 44,356 & 48,533 & 9 9* & 839 \\
\hline
\end{tabular}

Notes: Impacts are estimated using the inverse-probability-weighted regression adjustment (Doubly-robust estimator). Outcomes are measured in log-values to address to skewness towards large values (i.e., deal with outliers). The means presented in the table are geometric means in PKR. For each outcome of interest, the geometric mean is presented, as opposed to the arithmetic mean, as the former is better suited to deal with outliers and more accurate than using the median in small samples. ${ }^{\star \star \star} p<0.01 ;{ }^{*} p<0.05 ;{ }^{*} p<0.1$.

\section{Benefit-cost analysis}

AIR used the ingredients method for cost benefit analysis to assess whether the benefits of the PW-P program (the monetary gains created by the intervention of having plant clinics for farmers in treatment areas) outweigh the program costs.

All costs of implementation, including those often not adequately identified in budget or expenditure data, such as opportunity costs, or those shared between the program and other operational activities, were estimated. The costs associated with PW-P fall into three main categories: (a) CABI coordination and advocacy, (b) plant clinic operations, and (b) the Knowledge Bank and Plantwise Online Management System operations. For each of these sets of activities, the additional costs of PW-P (beyond the normal operating costs of the agricultural extension system) include the costs of investing in each of these activities-both to initiate the activities and to maintain them-as well as the opportunity costs of government employees' time. Costs for all three categories were totaled by year and funder. The total costs in 2017 were estimated to be GBP 694,236. In Table 2, program costs are totaled by year and funder and show how contribution by GOP increases over time reflecting the increasing number of clinics. All cost information used in this analysis was provided by CABI for the period 2012-2017. 
Table 2. Total PW-P Costs by Funder, 2012-2017

\begin{tabular}{|c|c|c|c|c|c|c|c|}
\hline & $\mathbf{2 0 1 2}$ & $\mathbf{2 0 1 3}$ & $\mathbf{2 0 1 4}$ & $\mathbf{2 0 1 5}$ & $\mathbf{2 0 1 6}$ & $\mathbf{2 0 1 7}$ & $\mathbf{2 0 1 8}$ \\
\hline Total & 145,580 & 145,923 & 294,186 & 496,753 & 631,304 & 694,237 & 723,968 \\
\hline Total CABI & 142,142 & 135,325 & 229,975 & 352,229 & 275,146 & 264,635 & 262,474 \\
\hline Total GOP & 3,438 & 10,598 & 64,211 & 144,524 & 356,158 & 429,602 & 461,494 \\
\hline
\end{tabular}

Benefits in 2017 are calculated from the estimated results of the impact assessment (see Figure 2). As shown, the calculation of program benefits focused exclusively on outcomes for farmers reporting a pest or crop disease in the past year, as this is the subpopulation for which the evaluation found an economically and statistically significant impact on the value of total production. Program benefits are estimated to be GBP 827,894. This gives a benefit-cost ratio for 2017 of $827,894 / 694,236$, or approximately 1.19:1, showing that the benefits outweighed the costs of running the program in 2017. Further, assuming that the costs and benefits remain stable after 2017, the benefit-cost ratio for the 2012-2024 period is 1.07:1. The benefit-cost ratio for 2012-2024 is lower than the ratio for 2017 because in the first years of program implementation there were very few plant clinics operating and therefore a much lower number of beneficiary farmers, while still having high start-up costs.

At present, $\mathrm{CABI}$ funds about one-third of the investment in PW-P through direct payments and the time of their staff. The opportunity costs of Ministry of Agriculture (MoA) staff time are covered by the Pakistan government. AIR conducted an additional benefit-cost analysis factoring in only those costs and activities that would be undertaken by the government should CABI transition out of ownership. If costs related to CABI coordination, advocacy, and salary top-ups are excluded, the total annual costs would become approximately $97 \%$ of current program costs, and the benefit-cost ratio for 2017 would increase to 1.28:1. Moreover, AIR also calculated the associated internal rate of return (IRR) of PW-P to be $28 \%{ }^{1}$

Figure 2: Benefit calculation

Benefits $=(A \times B)$
$\begin{aligned} & \mathrm{A}=\% \text { increase in annual value } \\ & \text { of production for farmers with } \\ & \text { pests or crop disease due to } \\ & \mathrm{PW}=\mathbf{9 \%}\end{aligned}$
$\begin{aligned} & \mathrm{C}=\text { Proportion of farmers } \\ & \text { reporting pests or crop disease } \\ & =\mathbf{2 3 \%}\end{aligned}$
$\begin{aligned} & \text { for control group } \\ & =\text { PKR 173,150 } \\ & \text { = GBP 933 }\end{aligned}$

\footnotetext{
1 The IRR is a measure used to estimate the profitability of an investment. It is calculated as the rate that makes the net present value of a project (i.e., benefits minus costs over a given period of time) equal to zero. According to the IRR criterion, an investment is profitable if the IRR is greater than the market rate of return (i.e., the market interest rate). That is, the higher a project's IRR, the more desirable it is to undertake. For the evaluation of PW-P, the IRR is estimated using the period from 2012 to 2024. the IRR was estimated using the following assumptions: (a) The number of plant clinics will remain stable for the period 2018-2024, (b) a plant clinic starts generating the observed full monetary benefits immediately, and (c) program benefits and costs will remain stable in real terms for the period 2018-2024. For additional details, see the impact assessment report.
} 


\section{Conclusion}

Evidence from the assessment of Plantwise impact in Pakistan firmly establishes that:

- Implementation of PW-P was as intended, and the trainings successfully prepared AOs to act as plant doctors and provide relevant advice to farmers. Plant clinics also increased AO's direct contact with farmers.

- The PW-P program has improved pest detection processes and responses to outbreaks for some farmers, and forecast the presence of pests and diseases for other farmers; but lacks the reach, scale, and influence to change systemic approaches for detection, control and response at provincial and national level.

- PW-P program has improved the adoption of positive agricultural practices, including safe pesticide usage among farmers who attended plant clinics

- PW-P also contributed to improvements in value of yields and net income for farmers who use plant clinics and who reported their crops having plant health issues.

- The benefits outweigh the costs of implementing the program at a benefit-cost ratio of 1.19:1

The Plantwise framework is therefore a cost-effective approach to improving a national plant health system, enabling smallholder farmers to produce more food sustainably with safer practices resulting also in improved crop productivity when there are plant health issues. 


\section{Acknowledgements}

This research brief was prepared by American Institutes for Research (AIR) on behalf of CABI. AIR is one of the world's largest behavioral and social science research and evaluation organizations. AIR's mission is to conduct and apply the best behavioral and social science research and evaluation towards improving people's lives, with a special emphasis on the disadvantaged.

AIR would like to acknowledge the support of the many organizations and people that contributed to the design, implementation, and production of this evaluation. CABI provided support on the design and implementation of the study. We thank DFID for providing the funding to CABI for carrying out the evaluation. We also thank the CABI Pakistan team, Pakistan Agriculture Research Council (PARC), National Agriculture Research Centre, Department of Agriculture Extension Punjab, Department of Plant Protection Punjab, and Department of Agriculture Extension Sindh for participating in interviews and providing valuable input and information to the study. We thank the farmers, agricultural extension officers, plant doctors, input suppliers, and district, provincial, national officials, and all those who support the implementation of the program in Pakistan.

$\mathrm{CABI}$ is an international intergovernmental organisation, and we gratefully acknowledge the core financial support from our member countries (and lead agencies) including the United Kingdom (Department for International Development), China (Chinese Ministry of Agriculture), Australia (Australian Centre for International Agricultural Research), Canada (Agriculture and Agri-Food Canada), Netherlands (Directorate-General for International Cooperation), and Switzerland (Swiss Agency for Development and Cooperation).

\section{Project donors}

Plantwise is supported by:

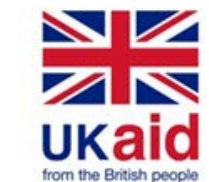

Irish Aid

Rialtas na hÉireann Government of Ireland

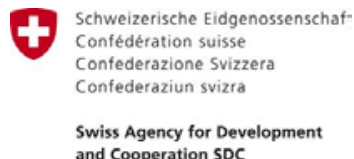

and Cooperation SDC

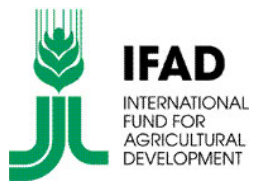

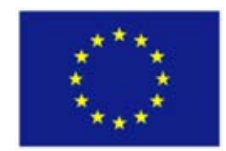

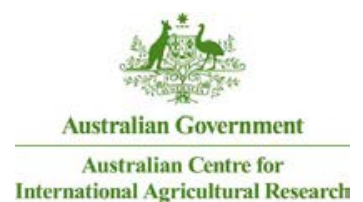

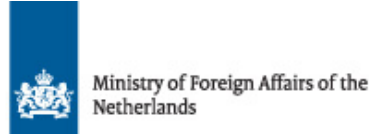

Ministry of Agriculture and

Rural Affairs (MARA)

People's Republic of China

\section{Project partners}

\section{Authors}

Juan Bonilla, PhD, American Institutes for Research

Andrea Coombes, MA, American Institutes for Research

Adria Molotsky, PhD, American Institutes for Research 


\section{Editorial team}

Dannie Romney, CABI

Frances Williams, CABI

\section{How to cite this paper}

Bonilla J., Coombes A. and Molotsky A. (2019) Plantwise Impact: Results and Lessons from Pakistan.

CABI Study Brief 33: Impact. DOI https://dx.doi.org/10.1079/CABICOMM-62-8120 